\title{
Protect, Repair, and Regenerate: Towards Restoring Vision in Glaucoma
}

\author{
Lauren K. Wareham ${ }^{1}$ - Michael L. Risner ${ }^{1}$. David J. Calkins ${ }^{1}$ (D) \\ Accepted: 23 October 2020 / Published online: 20 November 2020 \\ (C) The Author(s) 2020
}

\begin{abstract}
Purpose of Review We summarize recent advances in strategies that aim to restore optic nerve function and vision in glaucoma through protective, reparative, and regenerative avenues.

Recent Findings Neuroprotection relies on identification of early retinal ganglion cell dysfunction, which could prove challenging in the clinic. Cell replacement therapies show promise in restoring lost vision, but some hurdles remain in restoring visual circuitry in the retina and central connections in the brain.

Summary Identification and manipulation of intrinsic and extrinsic cellular mechanisms that promote axon regeneration in both resident and transplanted RGCs will drive future advances in vision restoration. Understanding the roles of multiple cell types in the retina that act in concert to promote RGC survival will aid efforts to promote neuronal health and restoration. Effective RGC transplantation, fine tuning axon guidance and growth, and synaptogenesis of transplanted and resident RGCs are still areas that require more research.
\end{abstract}

Keywords Optic nerve regeneration $\cdot$ Neuroregeneration $\cdot$ Neuroprotection $\cdot$ Glaucoma $\cdot$ Retinal ganglion cell $\cdot$ Neurorepair

\section{Introduction}

Glaucoma is treated as a disease of the anterior segment of the eye, since the only modifiable risk factor is intraocular pressure or IOP. Even so, vision loss in the disease arises from degeneration of the 1.5 million or so retinal ganglion cell (RGC) axons that comprise the optic nerve and form the optic projection to the brain [1]. Even with available hypotensive treatments, many patients with glaucoma continue to progress to sectors of irreversible vision loss and eventual blindness. Since early field defects typically do not affect central vision, glaucoma is often

This article is part of the Topical Collection on Diagnosis and Monitoring of Glaucoma

David J. Calkins

david.j.calkins@vumc.org

Lauren K. Wareham

lauren.wareham@vumc.org

Michael L. Risner

michael.1.risner@vumc.org

1 Department of Ophthalmology and Visual Sciences and the Vanderbilt Eye Institute, Vanderbilt University Medical Center, AA7100 MCN, 1161 21st Ave S., Nashville, TN 37232, USA unrecognized by patients until irrevocable damage to neural tissue has already occurred. Therapeutic interventions that target not IOP, but rather the causes of irreversible vision loss should incorporate three avenues corresponding to different points in progression: protection, repair, and regenerate (Fig. 1). Each avenue represents an important therapeutic window in disease progression with distinct characteristics and mechanistic targets. Identifying intrinsic and extrinsic mechanisms that can be leveraged to prevent RGC degeneration, repair dysfunctional cells, and promote regeneration of the optic nerve and projection requires understanding the signatures of IOP-related stress to the neural substrate, compensatory or adaptive responses to that stress, and processes that could be boot-strapped for tissue replacement during these windows. This review will highlight some recent advances in addressing RGC and optic nerve degeneration and will focus on the intrinsic responses that influence RGC axon survival, repair, and regeneration in glaucoma.

\section{The Optic Nerve Head-a Critical Locus for Degeneration and Potential Regeneration}

Sensitivity to IOP in glaucoma involves stress conveyed to RGC axons at the optic nerve head, which induces degenerative events in both distal and proximal structures [1]. In the 


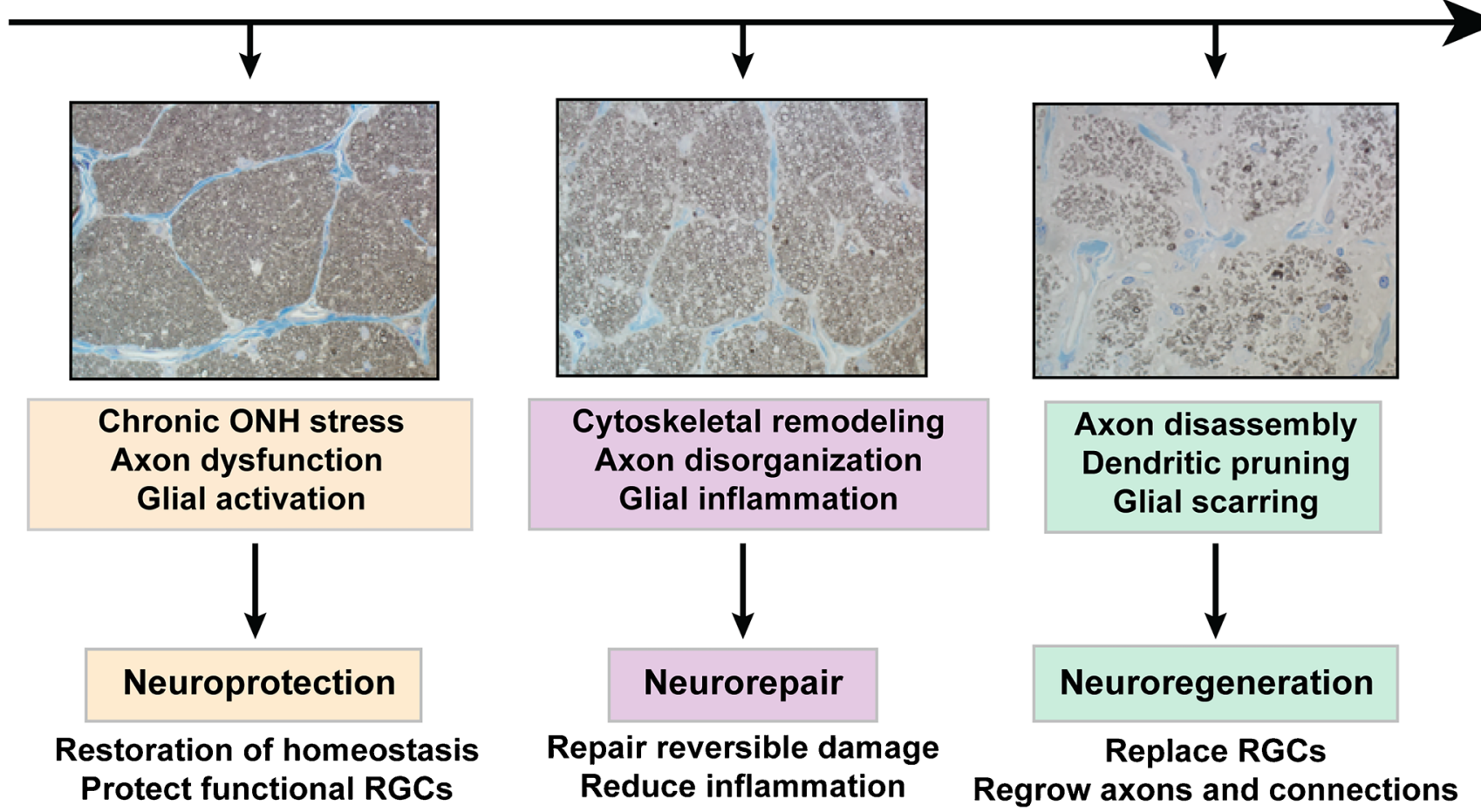

Fig. 1 Windows of opportunity for vision restoration in glaucoma. Crosssections through squirrel monkey optic nerve demonstrate stages of glaucoma. Early in disease progression, stressors at the optic nerve head lead to dysfunction of retinal ganglion cells (RGCs) and their axons and activation of glial cells in the retina and optic nerve. At this stage, neuroprotective strategies aim to restore homeostasis between dysfunctional RGCs and their environment and protect normally functioning RGCs from disease-relevant stress. As glaucoma progresses, early degenerative events include remodeling of cytoskeletal

retina and prelaminar region, $\mathrm{RGC}$ axons remain unmyelinated in well-defined bundles (or fascicles) that penetrate a plexus of astrocytes, capillaries, and connective tissues. In leaving the lamina cribrosa, RGC axons finally become myelinated, forming the optic nerve proper. The optic nerve head acts as a biological scaffold, a mesh of connective tissues and cells built to withstand changes in force, stress, and strain due to both fluctuations in IOP and its absolute magnitude [2]. Stress at the ONH conveyed to RGC axons leads to changes in activity, dendritic remodeling, axon atrophy, glial hypertrophy, and eventual glial scar formation.

Stress to RGCs in glaucoma progresses in both directions from the nerve head: retrograde towards the RGC body in the retina and anterograde towards central axonal targets in the brain. Work with transgenic mice demonstrates that the proximal (retrograde) and distal (anterograde) programs progressing on either side of this junction are to some extent independent [3-7]. In the retrograde direction, RGC dendritic arbors experience pruning, with loss of excitatory synapses. In the anterograde direction, active axonal transport from the retina to central brain terminals diminishes early in and synaptic structures throughout the RGC projection and increased inflammatory signaling from resident glial cells. At this stage in disease progression, therapies aim to repair reversible damage at the molecular and cellular level and to reduce inflammation to prevent further damage. Later stages include loss of RGCs and their axons with glial scarring in the optic nerve, which is a barrier to axon regeneration. Replacement therapies to restore visual function require RGC replacement and axon regeneration to appropriate central brain targets with remyelination in the optic nerve

progression, with subsequent disassembly of the myelinated axon in the nerve and degradation of post-synaptic targets in the brain $[8,9]$. Importantly, the unmyelinated axon segment in the retina and proximal nerve head remains intact along with the RGC body long after degeneration of the rest of the axon and pruning of the dendritic arbor. The optic nerve head is therefore a critical locus in the degeneration of RGCs and understanding the underlying mechanisms is key to developing protective, reparative, and regenerative strategies to preserve the optic projection and prevent vision loss in glaucoma.

\section{Early Glaucoma: Strategies to Protect RGCs}

Neuroprotective strategies aim to restore homeostasis between stressed RGCs and their environment in the optic projection to promote survival and protect unaffected RGCs from early progression. Animal studies involving either induced (e.g., microbead occlusion, [10]) or genetic (e.g., DBA/2J and GC$1^{-/-}$mice [10-12]) elevations in IOP have proven invaluable in identifying key molecular events in RGC dysfunction, which 
highlight an early window of neuroprotective opportunity. Ideally, neuroprotective strategies should prevent RGC dysfunction and thus subsequent degeneration while promoting repair or even regeneration of damaged tissue to restore vision, as reviewed elsewhere [13]. While clinical neuroprotective trials have proven difficult [14], therapies involving growth factors may have the potential to achieve those goals.

RGC dendrites are dynamic during development, expanding and contracting in response to environmental stimuli, but become stable when cells reach maturity [15]. Shrinkage of dendritic arbors occurs before complete degeneration of cells; thus, dendritic regeneration is a crucial step in the replenishment of RGC health and function $[16,17 \cdot \bullet]$. An important discovery is that RGCs possess the intrinsic ability to regenerate dendrites after injury; application of exogenous insulin after injury drives dendritic growth via the activation of the mammalian target of rapamycin (mTOR) pathway [17••]. Harnessing mTOR-driven regeneration of RGC dendrites may prove to be a useful neuroprotective strategy in glaucoma treatment in the future.

RGC axons extend a great distance from the retina to multiple termination zones in the brain. In murine models of glaucoma, dysfunctional axon transport is evident early in disease [9]. RGC axons rely on functional axonal transport for a plethora of neurotrophic factors, including brainderived neurotrophic factor (BDNF), nerve growth factor (NGF), and ciliary neurotrophic factor (CNTF) $[18,19]$. In glaucoma, transport of BDNF is compromised after elevations in IOP [20], while levels of BDNF are reduced in serum and tears of glaucoma patients [21, 22]. BDNF promotes the survival and growth of RGCs in vitro [23-25], while intravitreal injection of AAV2-derived BDNF significantly protected RGCs from degeneration following optic nerve transection and also improved optokinetic responses [26•]. Neurotrophin-based therapies have shown some efficacy in promoting RGC survival. NGF protects RGCs from injury in vitro [27, 28], while intravitreal administration of NGF and BDNF delays RGC death after acute optic nerve injury but does not prevent complete degeneration [29-31]. In a small study of patients with glaucoma, NGF eyedrops improved multiple aspects of visual acuity [32]. CNTF has some neuroprotective effects in vivo $[33,34]$ and is capable of stimulating axonal regeneration [35], which may be partially mediated by release of CNTF by astrocytes [36].

Although preclinical research into the neuroprotective effects of growth factors appears promising, one drawback to recombinant growth factor therapy appears to be the rapid clearance in vivo of exogenous neurotrophins, which are protein-based drugs and are highly sensitive to proteolytic degradation [37, 38]. Advancements in the development and use of viral vectors to overexpress neurotrophins in the retina may help to improve outcomes. Overexpression of BDNA or CNTF using viral vectors increases RGC survival after injury
$[26,39,40 \bullet, 41,42]$. Initial phase 1 clinical safety trials have shown that human CNTF is safe for human retinal tissue [43]. Recombinant NGF is in phase 1 clinical trials for glaucoma (Clinicaltrials.gov identifier: NCT02855450) after a previous clinical trial showed that topical delivery was well tolerated by patients [44]. While non-invasive retinal imaging utilizing a fluorescent biomarker of RGC apoptosis is helpful in tracking progression [45], translating preclinical findings into regular use for neuroprotection relies on earlier intervention by detecting more subtle changes in RGC function.

\section{Cell Replacement Strategies}

For patients with severe visual field deficits, indicative of gross RGC degeneration, strategies to replace lost RGCs may be the only way forward to restore vision. Photoreceptor replacement to restore vision provides proof-of-concept that integration of new neurons into the mammalian retina is possible [46-49], albeit without the complication of long-distance projection to multiple targets required of RGCs. Animal studies have already highlighted the challenges associated with transplanting RGCs into mature retinal tissue [50 $, 51,52 \bullet, 53-57]$. The generation and injection of healthy RGCs into a diseased eye is only the first step in a long and convoluted process of trying to reestablish the cellular connections needed to process visual information. Successful implantation would require healthy RGCs, accurate integration into retinal circuits, and axonal connections with appropriate areas in the brain. Injection of RGCs into the vitreous only results in less than $10 \%$ incorporation into the ganglion cell layer [58]. The inner limiting membrane (ILM) formed by Müller glia and astrocytes prevents facile integration both in vivo and in vitro $[57,59]$. Disruption by enzymatic digestion in explants improved dispersion of transplanted RGCs with a marked increase of neurite extension into retinal parenchyma [60]. Intravitreal injections themselves cause a localized inflammatory response, which may inhibit RGC survival. Once incorporated into the ganglion cell layer, the implanted RGCs need to form meaningful synaptic connections with other cells of the inner retina and produce an axon that can reach visual targets in the brain.

In terms of building new RGCs, there have been significant breakthroughs in the effort to generate pluripotent stems cells in recent years, including the developments of inducible pluripotent stem cells (iPSCs) from human fibroblasts [61]. These cells have an advantage over embryonic stem cells since they can be generated on a patient-specific basis, limiting the possibility of an unwanted immune response. Organoids derived from pluripotent stem-cells are self-organizing three-dimensional structures of cellular networks that form in vitro after supplementation with various growth and differentiation factors [62]. Retinal organoid cups recapitulate many of the aspects of vertebrate retinal development, including gene expression and retinal lamination 
[63-66]. Organoid-derived RGCs also exhibit photoreceptordriven action potentials comparable to the earliest light responses recorded from the neonatal mouse retina [67]. Planar-derived RGCs are transdifferentiated from pluripotent stem cells in culture [68], and after purification in culture have similar electrophysiological properties to native RGCs; hPSCRGCs demonstrate characteristic spontaneous and currentevoked activity, indicating functional axons; however, they do not develop the ability to form circuitry as RGCs in organoids do [69-71]. Co-culture of hPSC-RGCs with other cell types improves dendritic complexity and electrophysiological responses [72].

One major limitation to using iPSC-derived RGCs for transplantation is that generated cells will carry the same genetic susceptibility to degeneration as the donor. For example, iPSC-RGCs derived from a donor carrying a mutation in the optineuron gene implicated in normal-tension glaucoma will carry the same gene $[37,73]$. Generation of RGCs for transplantation may appear facile after discussion of the progress that has been made in the in vitro generation of RGCs; however, the retina harbors multiple retinal subtypes, each with distinct roles in the generation of visual signals [74]. Identifying the retinal subtypes that are most vulnerable to stress and degeneration in glaucoma is still challenging [14, 75]. Understanding how RGC cell types react to stress during progression will allow targeted production of specific types of RGCs, with better functional outcomes after transplantation and perhaps greater ability to produce axons capable of relaying signals to appropriate brain targets.

\section{Extrinsic Factors in RGC Axon Regeneration}

Mature retinal tissue is an extension of the central nervous system (CNS), which has a very low capacity to regenerate after injury due to both cell-intrinsic and cell-extrinsic factors. Following optic nerve crush, axons with modest sprouting may not extend sufficiently long distances and eventually die [76]. RGCs are surrounded by a complex network of supporting cells that promotes RGC function and survival. Even so, microglia and astrocytes in the optic nerve projection produce an early neuroprotective response following injury that can impede axon regeneration [77, 78]. Microglia are immediate responders to injury, where they become reactive and secrete TNF-a, Il-1a, and C1q that recruit astrocytes to the lesion site [79]. Astrocyte reactivity and proliferation are controlled by the signal transducer and activator of transcription protein-3 (STAT3), which is a member of the JAK/STAT signaling pathway [80]. STAT3 promotes glial scar formation from newly proliferated and activated astrocytes [81]. Astrocytes remodel and increase accumulations of neurofilaments and organelles and upregulate cell-cell communication pathways to recruit metabolic resources to the site of injury $[4,82,83 \bullet \cdot$. In spinal cord injury, glial scar formation may be initially neuroprotective by shielding neighboring uninjured axons from pro-apoptotic factors released by injured axons [84]. The removal of proliferating reactive astrocytes or genetic ablation of STAT3 accelerates axon degeneration [85]. Early inflammatory events in the retina can trigger axon regeneration; induction of inflammation by injection of zymosan into the eye or inflammation as a result of lens injury is sufficient to cause RGCs to regenerate axons through the injured optic nerve [86, 87]. Likewise, macrophage secretion of oncomodulin protein appears to promote intraocular inflammation and enhance optic nerve regeneration [88-90]. If the capacity of the retina to trigger an inflammatory response is reduced, i.e., by genetic deletion of two receptors that are expressed by inflammatory cells, Toll-like receptor 2 (TLR2) and dectin-1, then pro-regenerative effects of Zymosan injection are negated [91].

While early inflammation may benefit optic nerve regeneration, long-term glial scarring and inflammation inhibit axon growth. Reactive astrocytes and oligodendrocytes upregulate genes that inhibit axon regeneration directly or indirectly through activation of receptors on the surface of oligodendrocytes. These factors include chondroitin sulfate proteoglycans (CSPGs), Slit2, and ephrins [79, 92-94]. In healthy optic nerve, oligodendrocytes are myelinating glial cells that deposit myelin to help axon signal conductance; however, under pathogenic conditions, oligodendrocytes present a number of proteins that inhibit axon outgrowth including myelin-associated glycoprotein, oligodendrocyte myelin glycoprotein, and signaling through nogo receptors (NgR), [95-99]. Genetic deletion of NgR subtypes breaks this transduction pathway and enhances axon regrowth and motor activity after spinal cord injury; however, the results are subtle [100-102].

Late in progression, astrocyte processes fill in optic nerve volumes as glial scaring takes the place of degenerated axons [103]. Pioneering research has highlighted a far earlier role for astrocytes in providing support to injured RGC axons via metabolite redistribution in the optic nerve projection [83••]. Astrocytes are a known cellular support system for RGCs and their axons in the optic projection. Astrocytes respond to injury in the optic nerve by redistributing metabolic resources from healthy tissue via connexin-43 gap junctions [83••]. This study brings to light a novel mechanism by which astrocytes respond to axonal stress by providing auxiliary metabolic support, that if harnessed, could promote RGC survival and regeneration. Calcium-dependent astrocyte remodeling could allow focal redistribution of resources where needed [82, 104].

\section{Cell-Intrinsic Factors That Influence Regeneration}

During early development, RGC axon growth proceeds at a rapid rate to allow the extension of axons from the retina to reach distant targets in the brain. However, as RGCs transition 
from an embryonic to postnatal state, they reduce their axon growth speed by over 1000-fold [39]. External growthpromoting factors in the local RGC environment are the primary driving force for axon extension during RGC maturation but attempts to capture this process through exogenous growth factors after injury have been unsuccessful [105]. A confounding factor in exogenous growth factor application is that mature neurons show decreased responsiveness to growth factors and even more so after injury [106]. Control of axon growth is likely a complex interplay between extracellular signals and intrinsic RGC signaling pathways. If such intrinsic cellular pathways are identified and harnessed, progress could be made in encouraging RGCs to grow axons post-injury.

Targeting cell-intrinsic pathways to reprogram RGCs to a proaxogenic state have been met with more success. Several intrinsic molecular pathways can influence axonal growth including members of the Kruppel-like-factor transcription family. When overexpressed, Klf-4 and Klf-9 suppress axon outgrowth [107], while overexpression of Klf-6 and Klf-7 enhances axon outgrowth. After optic nerve injury in mice, conditional knockdown or deletion of Klf-4 promotes optic nerve regeneration $[107,108]$. A key molecular event that occurs during the maturation of RGCs is downregulated expression of phosphorylated mammalian target of rapamycin (phosphor-mTOR) [109]. Deletion of the mTOR inhibitor, phosphatase, and tensin homo$\log$ (PTEN) enhances the ability of neurons to regenerate after injury even in the absence of growth factors $[110,111]$. Combining the effects of the mTOR pathway with inhibition of SOCS3, a JAK/STAT3 inhibitor, further enhances RGC regeneration [112]. The mTOR pathway is a ubiquitous pathway that promotes the growth and survival of cells by regulating protein synthesis [113] and appears to act as a key regulator of optic nerve regeneration [114•]. Although approaches to harness intracellular pathways seem to promote long-distance RGC axon growth, a number of hurdles remain. Some therapies, such as targeting mTOR, thus far only favor axon regeneration of a subset of RGCs [115], which would have limited benefits in patients. Other avenues may harness activity-generating cation channels that may serve to boost RGC excitation to promote survival and growth [116].

\section{Axon Guidance and Synapse Formation}

Prompting axon regeneration from mature RGCs is a challenge in itself; once axon generation is initiated, the next hurdle is the correct direction of axon growth and generation of new synapses with targets in the brain. Efforts to regenerate axons have already demonstrated aberrant growth to improper targets $[112,117,118]$. Techniques using electric fields to direct axons to their targets have showed promise in vitro [119] and in vivo using nerve transection models [120-122], but safer application of electrical fields will determine whether this technique can be applied to humans [123]. An alternative approach using 3D-printed scaffolds to aid in axon guidance has been implemented in vitro $[69,124]$ but is in their infancy in their translation to the clinic.

As well as proper guidance to terminals, axons need to establish functional synapses in the diencephalon. Progress in this field is already hampered by limitations in longdistance axon regeneration. Going forward, understanding the process of synaptogenesis and cellular mechanisms involved in RGC development may help to promote synaptic development in regenerated RGCs. For example, in utero, developing RGCs are primed to respond to light stimulation by spontaneous neuronal activity called "retinal waves" [125]. This process drives voltage-dependent influx of calcium, which alters transcription of genes to promote synapse formation. Harnessing these developmental systems may promote synaptic formation in transplanted RGCs.

\section{Conclusions and Future Directions}

We face many challenges in trying to restore lost vision for patients with advanced glaucoma. The main focus of next generation glaucoma therapies is in the neuroprotection of RGCs to prevent vision loss and in cell replacement therapies to restore vision. Re-wiring the visual system is not a facile goal, the first obstacle lies in identifying windows of restorative opportunity. The earliest window of opportunity is when RGCs first become dysfunctional; in animal models, this is easily identified; however, in humans, it is more challenging to identify early RGC dysfunction. Currently, elevated IOP is the only indicator that RGCs are experiencing increased stress, and it is at this point that our neuroprotective strategies would be most effective. Further research into improved retinal imaging in the clinic would greatly enhance the efficacy of neuroprotective therapy by identifying early RGC dysfunction. It is unlikely that neuroprotective strategies alone will prevent RGC loss, since glaucoma patients often progress with the disease until visual defects occur.

Cell replacement therapy has long been a tantalizing prospect for many neurodegenerative diseases. The potential therapeutic value of RGCs derived from retinal organoids and planar systems is vigorously under investigation by numerous groups facilitated by the National Eye Institute's "Audacious Goals Initiate for Regenerative Medicine.” There are still hurdles to overcome however; for example, defining the most effective delivery system for donor cells into the host retina, examining how the introduction of foreign cells impacts the native retinal environment, and determining if donor RGCs integrate and form functional circuits that restore visual processing. The restoration of vision requires transplanted RGCs to grow axons that extend beyond the optic nerve head, remyelination by oligodendrocytes, and correct guidance to 
terminals in the brain where new synaptic formation can occur. RGCs do not function in isolation, relying on both cell intrinsic and extrinsic factors during disease to determine cell fate. In fact, RGCs rely on multiple cell types for survival in the optic tract. The novel finding that astrocytes directly act to provide neuroprotection during stress by shuttling metabolic resources further drives home this fact. Therefore, future progress in vision restoration will lie in harnessing the support mechanisms by other cells in the visual system to promote effective RGC transplantation and the formation of functional visual circuits.

Funding The authors express gratitude for support from Research to Prevent Blindness, Inc. (Unrestricted Departmental Grant, Stein Innovation Award to DJC), Glaucoma Research Foundation (Shaffer Award to LKW), and National Institutes of Health awards to DJC EY08126, EY017427, and EY024997.

Open Access This article is licensed under a Creative Commons Attribution 4.0 International License, which permits use, sharing, adaptation, distribution and reproduction in any medium or format, as long as you give appropriate credit to the original author(s) and the source, provide a link to the Creative Commons licence, and indicate if changes were made. The images or other third party material in this article are included in the article's Creative Commons licence, unless indicated otherwise in a credit line to the material. If material is not included in the article's Creative Commons licence and your intended use is not permitted by statutory regulation or exceeds the permitted use, you will need to obtain permission directly from the copyright holder. To view a copy of this licence, visit http://creativecommons.org/licenses/by/4.0/.

\section{References}

Papers of particular interest, published recently, have been highlighted as:

- Of importance

•- Of major importance

1. Calkins DJ. Critical pathogenic events underlying progression of neurodegeneration in glaucoma. Prog Retin Eye Res. 2012;31(6): 702-19. https://doi.org/10.1016/j.preteyeres.2012.07.001.

2. Burgoyne CF. A biomechanical paradigm for axonal insult within the optic nerve head in aging and glaucoma. Exp Eye Res. 2011;93(2):120-32. https://doi.org/10.1016/j.exer.2010.09.005.

3. Beirowski B, Babetto E, Coleman MP, Martin KR. The WldS gene delays axonal but not somatic degeneration in a rat glaucoma model. Eur J Neurosci. 2008;28(6):1166-79. https://doi.org/10. 1111/j.1460-9568.2008.06426.x.

4. Howell GR, Libby RT, Jakobs TC, Smith RS, Phalan FC, Barter $\mathrm{JW}$, et al. Axons of retinal ganglion cells are insulted in the optic nerve early in DBA/2J glaucoma. J Cell Biol. 2007;179(7):152337. https://doi.org/10.1083/jcb.200706181.

5. Howell GR, Soto I, Libby RT, John SW. Intrinsic axonal degeneration pathways are critical for glaucomatous damage. Exp Neurol. 2013;246:54-61. https://doi.org/10.1016/j.expneurol. 2012.01.014.

6. Schlamp CL, Li Y, Dietz JA, Janssen KT, Nickells RW. Progressive ganglion cell loss and optic nerve degeneration in
$\mathrm{DBA} / 2 \mathrm{~J}$ mice is variable and asymmetric. BMC Neurosci. 2006;7:66. https://doi.org/10.1186/1471-2202-7-66.

7. Soto I, Oglesby E, Buckingham BP, Son JL, Roberson ED, Steele $\mathrm{MR}$, et al. Retinal ganglion cells downregulate gene expression and lose their axons within the optic nerve head in a mouse glaucoma model. J Neurosci. 2008;28(2):548-61. https://doi.org/10. 1523/JNEUROSCI.3714-07.2008.

8. Vidal-Sanz M, Salinas-Navarro M, Nadal-Nicolas FM, AlarconMartinez L, Valiente-Soriano FJ, de Imperial JM, et al. Understanding glaucomatous damage: anatomical and functional data from ocular hypertensive rodent retinas. Prog Retin Eye Res. 2012;31(1):1-27. https://doi.org/10.1016/j.preteyeres.2011.08. 001.

9. Crish SD, Sappington RM, Inman DM, Horner PJ, Calkins DJ. Distal axonopathy with structural persistence in glaucomatous neurodegeneration. Proc Natl Acad Sci U S A. 2010;107(11): 5196-201. https://doi.org/10.1073/pnas.0913141107.

10. Chang B, Smith RS, Hawes NL, Anderson MG, Zabaleta A, Savinova $\mathrm{O}$, et al. Interacting loci cause severe iris atrophy and glaucoma in DBA/2J mice. Nat Genet. 1999;21(4):405-9.

11. Anderson MG, Smith RS, Hawes NL, Zabaleta A, Chang B, Wiggs JL, et al. Mutations in genes encoding melanosomal proteins cause pigmentary glaucoma in DBA/2J mice. Nat Genet. 2002;30(1):81-5. https://doi.org/10.1038/ng794.

12. Buys ES, Ko YC, Alt C, Hayton SR, Jones A, Tainsh LT, et al. Soluble guanylate cyclase alpha1-deficient mice: a novel murine model for primary open angle glaucoma. PLoS One. 2013;8(3): e60156. https://doi.org/10.1371/journal.pone.0060156.

13. Boia R, Ruzafa N, Aires ID, Pereiro X, Ambrosio AF, Vecino E, et al. Neuroprotective strategies for retinal ganglion cell degeneration: current atatus and challenges ahead. Int J Mol Sci. 2020;21(7). https://doi.org/10.3390/ijms21072262.

14. Ou Y, Jo RE, Ullian EM, Wong RO, Della SL. Selective vulnerability of specific retinal ganglion cell types and synapses after transient ocular hypertension. J Neurosci. 2016;36(35):9240-52. https://doi.org/10.1523/JNEUROSCI.0940-16.2016.

15. Koleske AJ. Molecular mechanisms of dendrite stability. Nat Rev Neurosci. 2013;14(8):536-50. https://doi.org/10.1038/nrn3486.

16. Fard MA, Afzali M, Abdi P, Yasseri M, Ebrahimi KB, Moghimi S. Comparison of the pattern of macular ganglion cell-inner plexiform layer defect between ischemic optic neuropathy and openangle glaucoma. Invest Ophthalmol Vis Sci. 2016;57(3):1011-6. https://doi.org/10.1167/iovs.15-18618.

17.• Agostinone J, Alarcon-Martinez L, Gamlin C, Yu WQ, Wong ROL, Di Polo A. Insulin signalling promotes dendrite and synapse regeneration and restores circuit function after axonal injury. Brain. 2018;141(7):1963-80. https://doi.org/10.1093/brain/ awy 142 This article provides the first evidence of an intrinsic ability of retinal ganglion cells to regenerate dendritic arbors after injury, via insulin-activation of the mTOR signaling pathway.

18. Fu L, Kwok SS, Chan YK, Ming Lai JS, Pan W, Nie L, et al. Therapeutic strategies for attenuation of retinal ganglion cell injury in optic neuropathies: concepts in translational research and therapeutic implications. Biomed Res Int. 2019;2019:8397521-10. https://doi.org/10.1155/2019/8397521.

19. Kimura A, Namekata K, Guo X, Harada C, Harada T. Neuroprotection, growth factors and BDNF-TrkB signalling in retinal degeneration. Int J Mol Sci. 2016;17(9):1584. https://doi. org/10.3390/ijms17091584.

20. Quigley HA, McKinnon SJ, Zack DJ, Pease ME, KerriganBaumrind LA, Kerrigan DF, et al. Retrograde axonal transport of BDNF in retinal ganglion cells is blocked by acute IOP elevation in rats. Invest Ophthalmol Vis Sci. 2000;41(11):3460-6.

21. Oddone F, Roberti G, Micera A, Busanello A, Bonini S, Quaranta L, et al. Exploring serum levels of brain derived neurotrophic 
factor and nerve growth factor across glaucoma stages. PLoS One. 2017;12(1):e0168565. https://doi.org/10.1371/journal.pone. 0168565 .

22. Ghaffariyeh A, Honarpisheh N, Shakiba Y, Puyan S, Chamacham $\mathrm{T}$, Zahedi $\mathrm{F}$, et al. Brain-derived neurotrophic factor in patients with normal-tension glaucoma. Optometry. 2009;80(11):635-8. https://doi.org/10.1016/j.optm.2008.09.014.

23. Mansour-Robaey S, Clarke DB, Wang YC, Bray GM, Aguayo AJ. Effects of ocular injury and administration of brain-derived neurotrophic factor on survival and regrowth of axotomized retinal ganglion cells. Proc Natl Acad Sci U S A. 1994;91(5):1632-6. https://doi.org/10.1073/pnas.91.5.1632.

24. Peinado-Ramon P, Salvador M, Villegas-Perez MP, Vidal-Sanz M. Effects of axotomy and intraocular administration of NT-4, NT-3, and brain-derived neurotrophic factor on the survival of adult rat retinal ganglion cells. A quantitative in vivo study. Invest Ophthalmol Vis Sci. 1996;37(4):489-500.

25. Pernet V, Di Polo A. Synergistic action of brain-derived neurotrophic factor and lens injury promotes retinal ganglion cell survival, but leads to optic nerve dystrophy in vivo. Brain. 2006;129(Pt 4):1014-26. https://doi.org/10.1093/brain/awl015.

26• . Chiha W, Bartlett CA, Petratos S, Fitzgerald M, Harvey AR. Intravitreal application of AAV-BDNF or mutant AAV-CRMP2 protects retinal ganglion cells and stabilizes axons and myelin after partial optic nerve injury. Exp Neurol. 2020;326:113167. https://doi.org/10.1016/j.expneurol.2019.113167 A recent study that demonstrates the capacity for BDNF to protect retinal ganglion cells after injury.

27. Colafrancesco V, Parisi V, Sposato V, Rossi S, Russo MA, Coassin M, et al. Ocular application of nerve growth factor protects degenerating retinal ganglion cells in a rat model of glaucoma. J Glaucoma. 2011;20(2):100-8. https://doi.org/10.1097/IJG. 0b013e3181d787e5.

28. Chen Q, Wang H, Liao S, Gao Y, Liao R, Little PJ, et al. Nerve growth factor protects retinal ganglion cells against injury induced by retinal ischemia-reperfusion in rats. Growth Factors. 2015;33(2):149-59. https://doi.org/10.3109/08977194.2015. 1010642.

29. McLaughlin T, O'Leary DD. Molecular gradients and development of retinotopic maps. Annu Rev Neurosci. 2005;28:327-55. https://doi.org/10.1146/annurev.neuro.28.061604.135714.

30. Symonds AC, King CE, Bartlett CA, Sauve Y, Lund RD, Beazley LD, et al. EphA5 and ephrin-A2 expression during optic nerve regeneration: a 'two-edged sword'. Eur J Neurosci. 2007;25(3): 744-52. https://doi.org/10.1111/j.1460-9568.2007.05321.x.

31. Gokoffski KK, Peng M, Alas B, Lam P. Neuro-protection and neuro-regeneration of the optic nerve: recent advances and future directions. Curr Opin Neurol. 2020;33(1):93-105. https://doi.org/ 10.1097/WCO.0000000000000777.

32. Lambiase A, Aloe L, Centofanti M, Parisi V, Bao SN, Mantelli F, et al. Experimental and clinical evidence of neuroprotection by nerve growth factor eye drops: implications for glaucoma. Proc Natl Acad Sci U S A. 2009;106(32):13469-74. https://doi.org/10. 1073/pnas.0906678106.

33. Pease ME, Zack DJ, Berlinicke C, Bloom K, Cone F, Wang Y, et al. Effect of CNTF on retinal ganglion cell survival in experimental glaucoma. Invest Ophthalmol Vis Sci. 2009;50(5):2194 200. https://doi.org/10.1167/iovs.08-3013.

34. Mathews MK, Guo Y, Langenberg P, Bernstein SL. Ciliary neurotrophic factor (CNTF)-mediated ganglion cell survival in a rodent model of non-arteritic anterior ischaemic optic neuropathy (NAION). Br J Ophthalmol. 2015;99(1):133-7. https://doi.org/ 10.1136/bjophthalmol-2014-305969.

35. Fischer D, Leibinger M. Promoting optic nerve regeneration. Prog Retin Eye Res. 2012;31(6):688-701. https://doi.org/10.1016/j. preteyeres.2012.06.005.
36. Muller A, Hauk TG, Fischer D. Astrocyte-derived CNTF switches mature RGCs to a regenerative state following inflammatory stimulation. Brain. 2007;130(Pt 12):3308-20. https://doi.org/10.1093/ brain/awm 257.

37. Gokoffski KK, Lam P, Alas BF, Peng MG, Ansorge HRR. Optic nerve regeneration: how will we get there? J Neuroophthalmol. 2020;40(2):234-42. https://doi.org/10.1097/WNO. 0000000000000953

38. Li R, Li DH, Zhang HY, Wang J, Li XK, Xiao J. Growth factorsbased therapeutic strategies and their underlying signaling mechanisms for peripheral nerve regeneration. Acta Pharmacol Sin. 2020;41:1289-300. https://doi.org/10.1038/s41401-019-0338-1.

39. Goldberg JL, Espinosa JS, Xu Y, Davidson N, Kovacs GT, Barres BA. Retinal ganglion cells do not extend axons by default: promotion by neurotrophic signaling and electrical activity. Neuron. 2002;33(5):689-702. https://doi.org/10.1016/s0896-6273(02) 00602-5.

40. Mesentier-Louro LA, Rosso P, Carito V, Mendez-Otero R, Santiago MF, Rama P, et al. Nerve growth factor role on retinal ganglion cell survival and axon regrowth: effects of ocular administration in experimental model of optic nerve injury. Mol Neurobiol. 2019;56(2):1056-69. https://doi.org/10.1007/s12035018-1154-1 A recent study that demonstrates that topical nerve growth factor application reaches posterior retinal targets and provides neuroprotective support to retinal ganglion cells after injury.

41. Martin KR, Quigley HA, Zack DJ, Levkovitch-Verbin H, Kielczewski J, Valenta D, et al. Gene therapy with brain-derived neurotrophic factor as a protection: retinal ganglion cells in a rat glaucoma model. Invest Ophthalmol Vis Sci. 2003;44(10):435765 .

42. Osborne A, Wang AXZ, Tassoni A, Widdowson PS, Martin KR. Design of a novel gene therapy construct to achieve sustained brain-derived neurotrophic factor signaling in neurons. Hum Gene Ther. 2018;29(7):828-41. https://doi.org/10.1089/hum. 2017.069.

43. Sieving PA, Caruso RC, Tao W, Coleman HR, Thompson DJ, Fullmer KR, et al. Ciliary neurotrophic factor (CNTF) for human retinal degeneration: phase I trial of CNTF delivered by encapsulated cell intraocular implants. Proc Natl Acad Sci U S A. 2006;103(10):3896-901. https://doi.org/10.1073/pnas. 0600236103

44. Ferrari MP, Mantelli F, Sacchetti M, Antonangeli MI, Cattani F, D'Anniballe G, et al. Safety and pharmacokinetics of escalating doses of human recombinant nerve growth factor eye drops in a double-masked, randomized clinical trial. BioDrugs. 2014;28(3): 275-83. https://doi.org/10.1007/s40259-013-0079-5.

45. Yap TE, Donna P, Almonte MT, Cordeiro MF. Real-time imaging of retinal ganglion cell apoptosis. Cells. 2018;7(6):60. https://doi. org/10.3390/cells7060060.

46. MacLaren RE, Pearson RA, MacNeil A, Douglas RH, Salt TE, Akimoto M, et al. Retinal repair by transplantation of photoreceptor precursors. Nature. 2006;444(7116):203-7. https://doi.org/10. 1038/nature05161.

47. Singh MS, Charbel Issa P, Butler R, Martin C, Lipinski DM, Sekaran S, et al. Reversal of end-stage retinal degeneration and restoration of visual function by photoreceptor transplantation. Proc Natl Acad Sci U S A. 2013;110(3):1101-6. https://doi.org/ 10.1073/pnas.1119416110.

48. Barber AC, Hippert C, Duran Y, West EL, Bainbridge JW, WarreCornish K, et al. Repair of the degenerate retina by photoreceptor transplantation. Proc Natl Acad Sci U S A. 2013;110(1):354-9. https://doi.org/10.1073/pnas.1212677110.

49. Pearson RA, Barber AC, Rizzi M, Hippert C, Xue T, West EL, et al. Restoration of vision after transplantation of photoreceptors. 
Nature. 2012;485(7396):99-103. https://doi.org/10.1038/ nature10997.

50. Wu S, Chang KC, Nahmou M, Goldberg JL. Induced pluripotent stem cells promote retinal ganglion cell survival after transplant. Invest Ophthalmol Vis Sci. 2018;59(3):1571-6. https://oi.org/ 10.1167/iovs.17-23648 An important study that shows that co-transplantation of human iPSC retinal ganglion cells with mouse retinal ganglion cells ex vivo and in vivo promotes increased survival of transplanted retinal ganglion cells, which suggests that human iPSCs have neuroprotective qualities.

51. Divya MS, Rasheed VA, Schmidt T, Lalitha S, Hattar S, James J. Intraocular injection of ES cell-derived neural progenitors improve visual function in retinal ganglion cell-depleted mouse models. Front Cell Neurosci. 2017;11:295. https://doi.org/10. 3389/fncel.2017.00295.

52.• Wang ST, Chen LL, Zhang P, Wang XB, Sun Y, Ma LX, et al. Transplantation of retinal progenitor cells from optic cup-like structures differentiated from human embryonic stem cells in vitro and in vivo generation of retinal ganglion-like cells. Stem Cells Dev. 2019;28(4):258-67. https://doi.org/10.1089/scd. 2018.0076 Important research that indicates that retinal progenitor cells derived from human stem cells can differentiate and incorporate into the mature retina in vivo.

53. Singhal S, Bhatia B, Jayaram H, Becker S, Jones MF, Cottrill PB, et al. Human Muller glia with stem cell characteristics differentiate into retinal ganglion cell (RGC) precursors in vitro and partially restore RGC function in vivo following transplantation. Stem Cells Transl Med. 2012;1(3):188-99. https://doi.org/10.5966/ sctm.2011-0005.

54. Becker S, Eastlake K, Jayaram H, Jones MF, Brown RA, McLellan GJ, et al. Allogeneic transplantation of Muller-derived retinal ganglion cells improves retinal function in a feline model of ganglion cell depletion. Stem Cells Transl Med. 2016;5(2): 192-205. https://doi.org/10.5966/sctm.2015-0125.

55. Chao JR, Lamba DA, Klesert TR, Torre A, Hoshino A, Taylor RJ, et al. Transplantation of human embryonic stem cell-derived retinal cells into the subretinal space of a non-human primate. Transl Vis Sci Technol. 2017;6(3):4. https://doi.org/10.1167/tvst.6.3.4.

56. Cho JH, Mao CA, Klein WH. Adult mice transplanted with embryonic retinal progenitor cells: new approach for repairing damaged optic nerves. Mol Vis. 2012;18:2658-72.

57. Hertz J, Qu B, Hu Y, Patel RD, Valenzuela DA, Goldberg JL. Survival and integration of developing and progenitor-derived retinal ganglion cells following transplantation. Cell Transplant. 2014;23(7):855-72. https://doi.org/10.3727/096368913X667024.

58. Venugopalan P, Wang Y, Nguyen T, Huang A, Muller KJ, Goldberg JL. Transplanted neurons integrate into adult retinas and respond to light. Nat Commun. 2016;7:10472. https://doi. org/10.1038/ncomms 10472 .

59. Johnson LN, Cashman SM, Kumar-Singh R. Cell-penetrating peptide for enhanced delivery of nucleic acids and drugs to ocular tissues including retina and cornea. Mol Ther. 2008;16(1):107-14. https://doi.org/10.1038/sj.mt.6300324.

60. Zhang KY, Tuffy C, Mertz JL, Quillen S, Wechsler L, Quigley HA, et al. Structural engraftment and topographic spacing of transplanted human stem cell-derived retinal ganglion cells; 2020. https://doi.org/10.1101/2020.07.14.196055.

61. Yu J, Vodyanik MA, Smuga-Otto K, Antosiewicz-Bourget J, Frane JL, Tian S, et al. Induced pluripotent stem cell lines derived from human somatic cells. Science. 2007;318(5858):1917-20. https://doi.org/10.1126/science.1151526.

62. Lidgerwood GE, Hewitt AW, Pebay A. Human pluripotent stem cells for the modelling of diseases of the retina and optic nerve: toward a retina in a dish. Curr Opin Pharmacol. 2019;48:114-9. https://doi.org/10.1016/j.coph.2019.09.003.
63. Gamm DM, Clark E, Capowski EE, Singh R. The role of FGF9 in the production of neural retina and RPE in a pluripotent stem cell model of early human retinal development. Am J Ophthalmol. 2019;206:113-31. https://doi.org/10.1016/j.ajo.2019.04.033.

64. Volkner M, Zschatzsch M, Rostovskaya M, Overall RW, Busskamp V, Anastassiadis K, et al. Retinal organoids from pluripotent stem cells efficiently recapitulate retinogenesis. Stem Cell Rep. 2016;6(4):525-38. https://doi.org/10.1016/j.stemcr.2016. 03.001 .

65. Fligor CM, Langer KB, Sridhar A, Ren Y, Shields PK, Edler MC, et al. Three-dimensional retinal organoids facilitate the investigation of retinal ganglion cell development, organization and neurite outgrowth from human pluripotent stem cells. Sci Rep. 2018;8(1): 14520. https://doi.org/10.1038/s41598-018-32871-8.

66. Meyer JS, Howden SE, Wallace KA, Verhoeven AD, Wright LS, Capowski EE, et al. Optic vesicle-like structures derived from human pluripotent stem cells facilitate a customized approach to retinal disease treatment. Stem Cells. 2011;29(8):1206-18. https:// doi.org/10.1002/stem.674.

67. Hallam D, Hilgen G, Dorgau B, Zhu L, Yu M, Bojic S, et al. Human-induced pluripotent stem cells generate light responsive retinal organoids with variable and nutrient-dependent efficiency. Stem Cells. 2018;36(10):1535-51. https://doi.org/10.1002/stem. 2883.

68. Lamba DA, Karl MO, Ware CB, Reh TA. Efficient generation of retinal progenitor cells from human embryonic stem cells. Proc Natl Acad Sci U S A. 2006;103(34):12769-74. https://doi.org/10. 1073/pnas.0601990103.

69. Sluch VM, Davis CH, Ranganathan V, Kerr JM, Krick K, Martin $\mathrm{R}$, et al. Differentiation of human ESCs to retinal ganglion cells using a CRISPR engineered reporter cell line. Sci Rep. 2015;5: 16595. https://doi.org/10.1038/srep16595.

70. Teotia P, Chopra DA, Dravid SM, Van Hook MJ, Qiu F, Morrison $\mathrm{J}$, et al. Generation of functional human retinal ganglion cells with target specificity from pluripotent stem cells by chemically defined recapitulation of developmental mechanism. Stem Cells. 2017;35(3):572-85. https://doi.org/10.1002/stem.2513.

71. VanderWall KB, Huang KC, Pan Y, Lavekar SS, Fligor CM, Allsop AR, et al. Retinal ganglion cells with a glaucoma OPTN(E50K) mutation exhibit neurodegenerative phenotypes when derived from three-dimensional retinal organoids. Stem Cell Rep. 2020;15(1):52-66. https://doi.org/10.1016/j.stemcr. 2020.05.009.

72. VanderWall KB, Vij R, Ohlemacher SK, Sridhar A, Fligor CM, Feder EM, et al. Astrocytes regulate the development and maturation of retinal ganglion cells derived from human pluripotent stem cells. Stem Cell Rep. 2019;12(2):201-12. https://doi.org/ 10.1016/j.stemcr.2018.12.010.

73. Ohlemacher SK, Sridhar A, Xiao Y, Hochstetler AE, Sarfarazi M, Cummins TR, et al. Stepwise differentiation of retinal ganglion cells from human pluripotent stem cells enables analysis of glaucomatous neurodegeneration. Stem Cells. 2016;34(6):155362. https://doi.org/10.1002/stem.2356.

74. Sanes JR, Masland RH. The types of retinal ganglion cells: current status and implications for neuronal classification. Annu Rev Neurosci. 2015;38:221-46. https://doi.org/10.1146/annurevneuro-071714-034120.

75. Feng L, Zhao Y, Yoshida M, Chen H, Yang JF, Kim TS, et al. Sustained ocular hypertension induces dendritic degeneration of mouse retinal ganglion cells that depends on cell type and location. Invest Ophthalmol Vis Sci. 2013;54(2):1106-17. https://doi.org/ 10.1167/iovs.12-10791.

76. Diekmann H, Leibinger M, Fischer D. Do growth-stimulated retinal ganglion cell axons find their central targets after optic nerve injury? New insights by three-dimensional imaging of the visual 
pathway. Exp Neurol. 2013;248:254-7. https://doi.org/10.1016/j. expneurol.2013.06.021.

77. Neufeld AH. Microglia in the optic nerve head and the region of parapapillary chorioretinal atrophy in glaucoma. Arch Ophthalmol. 1999;117(8):1050-6. https://doi.org/10.1001/ archopht.117.8.1050.

78. Yuan L, Neufeld AH. Activated microglia in the human glaucomatous optic nerve head. J Neurosci Res. 2001;64(5): 523-32. https://doi.org/10.1002/jnr.1104.

79. Liddelow SA, Guttenplan KA, Clarke LE, Bennett FC, Bohlen CJ, Schirmer L, et al. Neurotoxic reactive astrocytes are induced by activated microglia. Nature. 2017;541(7638):481-7. https://doi. org/10.1038/nature21029.

80. Zhang S, Li W, Wang W, Zhang SS, Huang P, Zhang C. Expression and activation of STAT3 in the astrocytes of optic nerve in a rat model of transient intraocular hypertension. PLoS One. 2013;8(1):e55683. https://doi.org/10.1371/journal.pone. 0055683.

81. Wanner IB, Anderson MA, Song B, Levine J, Fernandez A, GrayThompson Z, et al. Glial scar borders are formed by newly proliferated, elongated astrocytes that interact to corral inflammatory and fibrotic cells via STAT3-dependent mechanisms after spinal cord injury. J Neurosci. 2013;33(31):12870-86. https://doi.org/ 10.1523/JNEUROSCI.2121-13.2013.

82. Cooper ML, Crish SD, Inman DM, Horner PJ, Calkins DJ. Early astrocyte redistribution in the optic nerve precedes axonopathy in the DBA/2J mouse model of glaucoma. Exp Eye Res. 2016;150: 22-33. https://doi.org/10.1016/j.exer.2015.11.016.

83.• Cooper ML, Pasini S, Lambert WS, D'Alessandro KB, Yao V, Risner ML, et al. Redistribution of metabolic resources through astrocyte networks mitigates neurodegenerative stress. Proc Natl Acad Sci U S A. 2020;117(31):18810-21. https://doi.org/10. 1073/pnas.2009425117 Pioneering study that demonstrates a very early role for astrocytes after injury in redistributing metabolic resources from healthy to compromised tissue in the optic projection.

84. Bradbury EJ, Burnside ER. Moving beyond the glial scar for spinal cord repair. Nat Commun. 2019;10(1):3879. https://doi.org/ 10.1038/s41467-019-11707-7.

85. Anderson MA, Burda JE, Ren Y, Ao Y, O'Shea TM, Kawaguchi $\mathrm{R}$, et al. Astrocyte scar formation aids central nervous system axon regeneration. Nature. 2016;532(7598):195-200. https://doi.org/ 10.1038 /nature17623.

86. Leon S, Yin Y, Nguyen J, Irwin N, Benowitz LI. Lens injury stimulates axon regeneration in the mature rat optic nerve. $\mathrm{J}$ Neurosci. 2000;20(12):4615-26.

87. Yin Y, Cui Q, Li Y, Irwin N, Fischer D, Harvey AR, et al. Macrophage-derived factors stimulate optic nerve regeneration. J Neurosci. 2003;23(6):2284-93.

88. Yin Y, Cui Q, Gilbert HY, Yang Y, Yang Z, Berlinicke C, et al. Oncomodulin links inflammation to optic nerve regeneration. Proc Natl Acad Sci U S A. 2009;106(46):19587-92. https://doi.org/10. 1073/pnas.0907085106.

89. Kurimoto T, Yin Y, Omura K, Gilbert HY, Kim D, Cen LP, et al. Long-distance axon regeneration in the mature optic nerve: contributions of oncomodulin, cAMP, and pten gene deletion. J Neurosci. 2010;30(46):15654-63. https://doi.org/10.1523/ JNEUROSCI.4340-10.2010.

90. Yin Y, Henzl MT, Lorber B, Nakazawa T, Thomas TT, Jiang F, et al. Oncomodulin is a macrophage-derived signal for axon regeneration in retinal ganglion cells. Nat Neurosci. 2006;9(6):84352. https://doi.org/10.1038/nn1701.

91. Baldwin KT, Carbajal KS, Segal BM, Giger RJ. Neuroinflammation triggered by beta-glucan/dectin-1 signaling enables CNS axon regeneration. Proc Natl Acad Sci U S A. 2015;112(8):2581-6. https://doi.org/10.1073/pnas.1423221112.
92. McKeon RJ, Schreiber RC, Rudge JS, Silver J. Reduction of neurite outgrowth in a model of glial scarring following CNS injury is correlated with the expression of inhibitory molecules on reactive astrocytes. J Neurosci. 1991;11(11):3398-411.

93. Fabes J, Anderson P, Yanez-Munoz RJ, Thrasher A, Brennan C, Bolsover S. Accumulation of the inhibitory receptor EphA4 may prevent regeneration of corticospinal tract axons following lesion. Eur J Neurosci. 2006;23(7):1721-30. https://doi.org/10.1111/j. 1460-9568.2006.04704.x.

94. Hara M, Kobayakawa K, Ohkawa Y, Kumamaru H, Yokota K, Saito T, et al. Interaction of reactive astrocytes with type I collagen induces astrocytic scar formation through the integrin-N-cadherin pathway after spinal cord injury. Nat Med. 2017;23(7):818-28. https://doi.org/10.1038/nm.4354.

95. Schwab ME, Thoenen H. Dissociated neurons regenerate into sciatic but not optic nerve explants in culture irrespective of neurotrophic factors. J Neurosci. 1985;5(9):2415-23.

96. McKerracher L, David S, Jackson DL, Kottis V, Dunn RJ, Braun PE. Identification of myelin-associated glycoprotein as a major myelin-derived inhibitor of neurite growth. Neuron. 1994;13(4): 805-11. https://doi.org/10.1016/0896-6273(94)90247-x.

97. Prinjha R, Moore SE, Vinson M, Blake S, Morrow R, Christie G, et al. Inhibitor of neurite outgrowth in humans. Nature. 2000;403(6768):383-4. https://doi.org/10.1038/35000287.

98. Wang KC, Koprivica V, Kim JA, Sivasankaran R, Guo Y, Neve $\mathrm{RL}$, et al. Oligodendrocyte-myelin glycoprotein is a Nogo receptor ligand that inhibits neurite outgrowth. Nature. 2002;417(6892): 941-4. https://doi.org/10.1038/nature00867.

99. Benson MD, Romero MI, Lush ME, Lu QR, Henkemeyer M, Parada LF. Ephrin-B3 is a myelin-based inhibitor of neurite outgrowth. Proc Natl Acad Sci U S A. 2005;102(30):10694-9. https://doi.org/10.1073/pnas.0504021102.

100. Kim JE, Li S, GrandPre T, Qiu D, Strittmatter SM. Axon regeneration in young adult mice lacking Nogo-A/B. Neuron. 2003;38(2): 187-99. https://doi.org/10.1016/s0896-6273(03)00147-8.

101. Simonen M, Pedersen V, Weinmann O, Schnell L, Buss A, Ledermann B, et al. Systemic deletion of the myelin-associated outgrowth inhibitor Nogo-A improves regenerative and plastic responses after spinal cord injury. Neuron. 2003;38(2):201-11. https://doi.org/10.1016/s0896-6273(03)00226-5.

102. Dickendesher TL, Baldwin KT, Mironova YA, Koriyama Y, Raiker SJ, Askew KL, et al. NgR1 and $\mathrm{NgR} 3$ are receptors for chondroitin sulfate proteoglycans. Nat Neurosci. 2012;15(5):70312. https://doi.org/10.1038/nn.3070.

103. Bosco A, Breen KT, Anderson SR, Steele MR, Calkins DJ, Vetter ML. Glial coverage in the optic nerve expands in proportion to optic axon loss in chronic mouse glaucoma. Exp Eye Res. 2016;150:34-43. https://doi.org/10.1016/j.exer.2016.01.014.

104. Ho KW, Lambert WS, Calkins DJ. Activation of the TRPV1 cation channel contributes to stress-induced astrocyte migration. Glia. 2014;62(9):1435-51. https://doi.org/10.1002/glia.22691.

105. Thoenen H, Sendtner M. Neurotrophins: from enthusiastic expectations through sobering experiences to rational therapeutic approaches. Nat Neurosci. 2002;5(Suppl):1046-50. https://doi.org/ 10.1038/nn938.

106. Belin S, Nawabi H, Wang C, Tang S, Latremoliere A, Warren P, et al. Injury-induced decline of intrinsic regenerative ability revealed by quantitative proteomics. Neuron. 2015;86(4):1000-14. https://doi.org/10.1016/j.neuron.2015.03.060.

107. Moore DL, Blackmore MG, Hu Y, Kaestner KH, Bixby JL, Lemmon VP, et al. KLF family members regulate intrinsic axon regeneration ability. Science. 2009;326(5950):298-301. https:// doi.org/10.1126/science.1175737.

108. Qin S, Zou Y, Zhang CL. Cross-talk between KLF4 and STAT3 regulates axon regeneration. Nat Commun. 2013;4:2633. https:// doi.org/10.1038/ncomms3633. 
109. Laha B, Stafford BK, Huberman AD. Regenerating optic pathways from the eye to the brain. Science. 2017;356(6342):10314. https://doi.org/10.1126/science.aal5060.

110. Park KK, Liu K, Hu Y, Smith PD, Wang C, Cai B, et al. Promoting axon regeneration in the adult CNS by modulation of the PTEN/mTOR pathway. Science. 2008;322(5903):963-6. https://doi.org/10.1126/science.1161566.

111. Zukor K, Belin S, Wang C, Keelan N, Wang X, He Z. Short hairpin RNA against PTEN enhances regenerative growth of corticospinal tract axons after spinal cord injury. J Neurosci. 2013;33(39):15350-61. https://doi.org/10.1523/JNEUROSCI. 2510-13.2013.

112. Sun F, Park KK, Belin S, Wang D, Lu T, Chen G, et al. Sustained axon regeneration induced by co-deletion of PTEN and SOCS3. Nature. 2011;480(7377):372-5. https://doi.org/10.1038/ nature10594.

113. Costa-Mattioli M, Monteggia LM. mTOR complexes in neurodevelopmental and neuropsychiatric disorders. Nat Neurosci. 2013;16(11):1537-43. https://doi.org/10.1038/nn.3546.

114. Teotia P, Van Hook MJ, Fischer D, Ahmad I. Human retinal ganglion cell axon regeneration by recapitulating developmental mechanisms: effects of recruitment of the mTOR pathway. Development. 2019;146(13):dev178012. https://doi.org/10.1242/ dev.178012 A study that highlights the importance of the mTOR pathway in RGC axon regeneration after injury.

115. Duan X, Qiao M, Bei F, Kim IJ, He Z, Sanes JR. Subtype-specific regeneration of retinal ganglion cells following axotomy: effects of osteopontin and mTOR signaling. Neuron. 2015;85(6):1244 56. https://doi.org/10.1016/j.neuron.2015.02.017.

116. Sappington RM, Sidorova T, Ward NJ, Chakravarthy R, Ho KW, Calkins DJ. Activation of transient receptor potential vanilloid-1 (TRPV1) influences how retinal ganglion cell neurons respond to pressure-related stress. Channels (Austin). 2015;9(2):102-13. https://doi.org/10.1080/19336950.2015.1009272.

117. Luo X, Salgueiro Y, Beckerman SR, Lemmon VP, Tsoulfas P, Park KK. Three-dimensional evaluation of retinal ganglion cell axon regeneration and pathfinding in whole mouse tissue after injury. Exp Neurol. 2013;247:653-62. https://doi.org/10.1016/j. expneurol.2013.03.001.

118. Pernet V, Joly S, Dalkara D, Jordi N, Schwarz O, Christ F, et al. Long-distance axonal regeneration induced by CNTF gene transfer is impaired by axonal misguidance in the injured adult optic nerve. Neurobiol Dis. 2013;51:202-13. https://doi.org/10.1016/j. nbd.2012.11.011.

119. Gokoffski KK, Jia X, Shvarts D, Xia G, Zhao M. Physiologic electrical fields direct retinal ganglion cell axon growth in vitro. Invest Ophthalmol Vis Sci. 2019;60(10):3659-68. https://doi.org/ 10.1167/iovs.18-25118.

120. Borgens RB, Roederer E, Cohen MJ. Enhanced spinal cord regeneration in lamprey by applied electric fields. Science. 1981;213(4508):611-7. https://doi.org/10.1126/science.7256258.

121. Borgens RB, Bohnert DM. The responses of mammalian spinal axons to an applied DC voltage gradient. Exp Neurol. 1997;145(2 Pt 1):376-89. https://doi.org/10.1006/exnr.1997.6499.

122. Graves MS, Hassell T, Beier BL, Albors GO, Irazoqui PP. Electrically mediated neuronal guidance with applied alternating current electric fields. Ann Biomed Eng. 2011;39(6):1759-67. https://doi.org/10.1007/s10439-011-0259-8.

123. Merrill DR, Bikson M, Jefferys JG. Electrical stimulation of excitable tissue: design of efficacious and safe protocols. J Neurosci Methods. 2005;141(2):171-98. https://doi.org/10.1016/j. jneumeth.2004.10.020.

124. Yang TC, Chuang JH, Buddhakosai W, Wu WJ, Lee CJ, Chen WS, et al. Elongation of axon extension for human iPSC-derived retinal ganglion cells by a nano-imprinted scaffold. Int J Mol Sci. 2017;18(9):2013. https://doi.org/10.3390/ijms18092013.

125. Ackman JB, Crair MC. Role of emergent neural activity in visual map development. Curr Opin Neurobiol. 2014;24(1):166-75. https://doi.org/10.1016/j.conb.2013.11.011.

Publisher's Note Springer Nature remains neutral with regard to jurisdictional claims in published maps and institutional affiliations. 